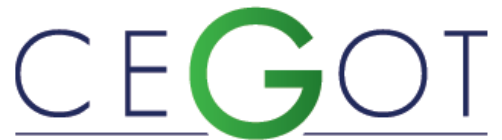

Centro de Estudos de Geografia e Ordenamento do Território
Geografia e Ordenamento do Território, Revista Eletrónica Centro de Estudos de Geografia e Ordenamento do Território http://cegot.org

LIBERTI, EDUARDO

Universidade Federal do Paraná, Departamento de Geografia,

Programa de Pós-Graduação em Geografia

Rua Cel. Francisco H. Dos Santos, S/N, 81.530-900, Bairro Jardim das

Américas, Curitiba, Paraná, Brasil

eduardoliberti@hotmail.com

ESTÊVEZ, LAURA

Universidade Federal do Paraná, Departamento de Geografia, Programa de Pós-Graduação em Geografia

Rua Cel. Francisco H. Dos Santos, S/N, 81.530-900, Bairro Jardim das Américas, Curitiba, Paraná, Brasil

laurafreire.geo@gmail.com

NUCCI, JOÃO

Universidade Federal do Paraná, Departamento de Geografia, Programa de Pós-Graduação em Geografia

Rua Cel. Francisco H. Dos Santos, S/N, 81.530-900, Bairro Jardim das

Américas, Curitiba, Paraná, Brasil

jenucci@gmail.com

\title{
Mapeamento do uso da terra e da qualidade ambiental urbana da parte superior da bacia hidrográfica do rio Belém, Curitiba, Estado do Paraná, Brasil \\ Land Use Mapping and Urban Environmental Quality Mapping to upper part of the Belém river basin, Curitiba, State of Paraná, Brazil
}

Referência: Liberti, Eduardo; Estêvez, Laura; Nucci, João (2019). Mapeamento do uso da terra e da qualidade ambiental urbana da parte superior da bacia hidrográfica do rio Belém, Curitiba, Estado do Paraná, Brasil. Revista de Geografia e Ordenamento do Território (GOT), n. ${ }^{\circ} 16$ (março). Centro de Estudos de Geografia e Ordenamento do Território, p. 177-201, dx.doi.org/10.17127/got/2019.16.008

\section{RESUMO}

Os variados usos da terra nas cidades, reflexo das atividades humanas e políticas públicas, acasionam alterações na paisagem e, consequentemente, na qualidade ambiental urbana. Com base na classificação proposta por Nucci et al. (2017), mapeou-se, lote a lote, a utilização da terra da parte superior da bacia hidrográfica do rio Belém em Curitiba/Paraná/Brasil e construiu-se uma carta de qualidade ambiental da área. Como resultados pôde-se espacializar e discutir como configura-se a qualidade ambiental da área de estudo, demonstrando diversificados conflitos entre os usos da terra. A classificação proposta, que relaciona o uso da terra com a qualidade ambiental urbana, demonstrou-se de fácil aplicação e entendimento, constituindo-se como uma importante ferramenta, tanto para o planejamento e gestão urbana como para a participação popular nesse processo.

Palavras-chave: Ecologia Urbana; Planejamento da Paisagem; Ecologia da Paisagem; Ambiente Urbano; Paisagem Urbana.

\section{ABSTRACT}


The diferent uses of land in cities, a reflection of human activities and public policies, affect changes in the landscape and, consequently, in the urban environmental quality. Based on the classification proposed by Nucci et al. (2017), the land use of the upper part of the Belém river basin in Curitiba/Paraná/Brazil was mapped, lot by lot, and a map of the area's environmental quality was constructed. As a result, it was possible to spatialize and discuss how the environmental quality of the study area is configured, demonstrating several conflicts between land uses. The proposed classification, which relates land use to urban environmental quality, has been shown to be easy to apply and understand, constituting an important tool for urban planning and management as well as for popular participation in this process.

Keywords: Urban Ecology; Landscape Planning; Landscape Ecology; Urban Environment; Urban Landscape.

\section{Introdução}

O acelerado crescimento da população dos centros urbanos tem ocasionado alterações significativas na paisagem, devido ao constante aumento de edificações, das vias de tráfego e toda infraestrutura relacionada, resultando, consequentemente, no decorrer deste processo, em modificações negativas para a qualidade ambiental (TONETTI, 2011).

Os estudos relacionados com a qualidade ambiental urbana proporcionam informações relevantes no que se refere ao entendimento dos problemas ambientais resultantes do rápido crescimento do processo de urbanização. Estêvez e Nucci (2015, p. 27) afirmam que "com base nas avaliações da qualidade ambiental urbana, é possível tomar decisões de planejamento e gestão que busquem diminuir ou mesmo evitar os impactos causados por ações antrópicas sobre o ambiente urbano".

Para a avaliação da qualidade ambiental, o mapeamento do uso e da cobertura da terra do ambiente urbano constitui-se como uma significativa ferramenta. Pauleit e Breuste (2011) afirmam que o uso e a cobertura da terra são componentes importantes que entram na composição da estrutura das paisagens, interferindo em suas dinâmicas e, consequentemente, em suas qualidades. Assim, conhecer como se distribui os tipos de uso e cobertura da terra, assim como suas dinâmicas é de suma importância para guiar a utilização do ambiente (VALASKI; NUCCI, 2018). 
Nesse contexto, o Planejamento da Paisagem, segundo Kiemstedt et al. (1998), considerado como um importante instrumento intimamente relacionado à qualidade ambiental urbana, e tendo por objetivo garantir de maneira sustentável e contínua a capacidade funcional dos ecossistemas e a forma das paisagens, pode fornecer importante contribuição para a vida humana nas cidades.

Os estudos que tratam da qualidade ambiental urbana relacionados com o Planejamento da Paisagem, um instrumento legal instituído na Alemanha, apresentam como um dos seus objetivos a definição de recomendações sobre metas de qualidade ambiental e sobre critérios para Avaliação de Impacto Ambiental (HAAREN, et al., 2008). O Planejamento da Paisagem representa um instrumento central de planejamento visando à conservação da natureza, em áreas urbanizadas ou não, tendo o "objetivo de salvaguardar a capacidade dos ecossistemas e o potencial recreativo da paisagem como partes fundamentais para a vida humana" (NUCCl, 2008, p.9).

Alberti (2008) afirma que o uso da terra e seus impactos ecológicos são uma função dos padrões espaciais das atividades humanas e habitats naturais, que afetam os processos ecológicos e socioeconômicos em várias escalas. De acordo com Nucci (2008), a qualidade do ambiente urbano está diretamente relacionada aos usos existentes na cidade. Assim, o mapeamento do uso da terra torna-se uma importante etapa para realizar inferências sobre a qualidade ambiental, pois, uma vez elegendo os usos potenciais causadores de poluição, bastaria localizá-los espacialmente e mapear as áreas potencialmente poluídas. Para Nucci (2008), essa etapa seria considerada como um procedimento inicial, rápido, preventivo e de baixo custo no planejamento da paisagem urbana, já que o levantamento direto da poluição no ambiente é muito mais complexo e oneroso.

Mota (1999) ressalta que esse tipo de indicação geral dos usos potencialmente poluidores seria muito útil na fase de planejamento, devendo existir estudos mais detalhados na fase de implantação.

As inferências sobre a qualidade ambiental são efetuadas com base em uma ampla revisão bibliográfica de vários estudos empíricos e teóricos sobre as consequências da urbanização para a qualidade do ar, da água, do solo, da vegetação e da fauna, podendo-se citar obras importantes na área da Geografia Física Urbana, Ecologia Urbana e Urbanismo como, por 
exemplo, McHarg (1971), Marcus e Detwyler (1972), Douglas (1983), Sukopp e Werner (1991), Cavalheiro (1991), Spirn (1995) e Hough (1998), entre outras.

De acordo com os estudos citados, o controle do uso e da cobertura da terra nas cidades é de fundamental importância para a qualidade ambiental urbana, esse controle geralmente é realizado por leis federais, estaduais e municipais, sendo as leis de zoneamento municipais ou Leis de Uso e Ocupação do Solo (LUOS) as que concentram a legislação das outras esferas de poder e agem mais diretamente nas zonas urbanas do município (NUCCl et al., 2017).

Conforme explicam Nucci et al. (2017), os textos, quadros e mapas característicos das LUOS são muito complexos para o entendimento do cidadão leigo e apenas tangenciam as questões relacionadas com a qualidade ambiental urbana, sendo necessária uma tradução simplificadora do conteúdo dessas leis e que relacione as tipologias de uso e de cobertura da terra com níveis de qualidade ambiental.

De acordo com uma proposta de legenda desenvolvida por Nucci et al. (2017) para realizar a classificação do uso da terra, foram definidos, com base em pesquisas bibliográficas relacionadas a leis municipais de uso e ocupação do solo, os critérios e parâmetros que favorecem estabelecer a correlação entre a qualidade ambiental urbana conforme o uso da terra. Para isso, houve uma hierarquização dos tipos de usos de acordo com as potencialidades em gerar alterações na qualidade do ambiente.

Cabe destacar que a participação popular é considerada de fundamental importância para o Planejamento da Paisagem, assim, tal proposta de legenda apresenta-se como uma valorosa ferramenta facilitadora para o entendimento sobre dinâmica da paisagem e sua qualidade por parte da população.

Com a finalidade de testar a proposta de legenda de Nucci et al. (2017), construiu-se uma carta de qualidade ambiental com base na identificação e mapeamento do uso da terra, utilizando como recorte espacial a parte superior da bacia do rio Belém - Curitiba/Paraná. 


\section{Procedimentos Metodológicos}

A área de estudo refere-se a parte superior da bacia hidrográfica do rio Belém, localizada na região norte do município de Curitiba/Paraná/Brasil, abrangendo parte dos bairros Abranches, Barreirinha, Cachoeira e Taboão, compreendendo uma área de aproximadamente $3,48 \mathrm{~km}^{2}$ (Figura 1 ).

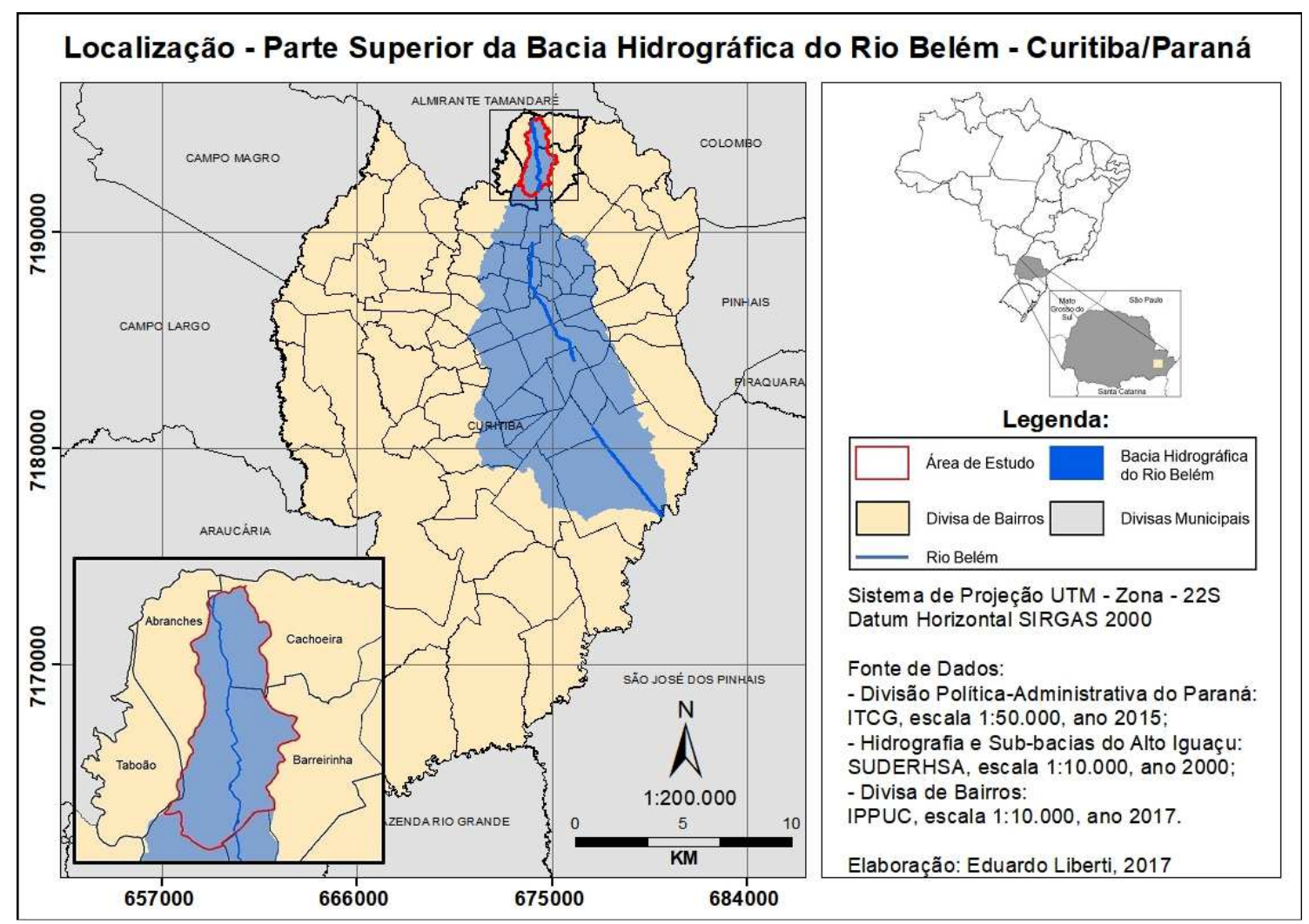

Figura 1 - Localização da área de estudo - parte superior da bacia hidrográfica do Rio Belém (Curitiba/Paraná). Organização: os autores, 2017.

A definição desse recorte espacial é justificada pela relevância de sua localização geográfica, uma vez que abrange as nascentes do Rio Belém, descrita por Bollmann e Edwiges (2008, p.447) como uma área que abriga "[...] remanescentes importantes da cobertura vegetal original em variados estágios de antropização. É também uma região contrastante em termos de sua ocupação". Além disso, estudos realizados anteriormente no local demonstraram uma ampla e diferenciada gama de usos e cobertura da terra, constituindose em uma área oportuna e pertinente ao estudo proposto.

Para a construção da base cartográfica utilizaram-se dados geoespaciais vetoriais em formato shapefile de lotes, quadras e arruamento, disponibilizados pelo Instituto de 
Pesquisa e Planejamento Urbano de Curitiba (IPPUC), do ano de 2017, na escala 1:10.000, na projeção UTM e Datum SAD69, posteriormente convertido para SIRGAS2000.

Para a delimitação do polígono da área de estudo utilizou-se como base o dado geoespacial vetorial em formato shapefile, referente às curvas de nível, na escala 1:10.000, do ano 2000, disponibilizado pelo Instituto das Águas do Paraná (SUDERHSA).

Inicialmente fez-se o levantamento dos diferenciados usos da terra lote a lote, utilizando-se como base para a identificação dos mesmos as imagens em $360^{\circ}$ na horizontal e $290^{\circ}$ na vertical, referentes ao recurso do Google Street View, disponíveis nos anos de 2011 a 2017. Tal recurso possibilita a visualização e identificação ao nível do solo dos lotes classificados.

Um trabalho de campo foi realizado em agosto de 2017 para validar in loco alguns usos indetermináveis pela observação das imagens, como, por exemplo, lotes que aparentemente representavam usos comerciais ou de serviços, porém estavam sem identificação visual de placas, letreiros ou banners ou mesmo encontravam-se fechados.

Houve casos no qual a identificação dos usos não foi possível, como, por exemplo, lotes com características comerciais ou de serviços, porém fechados, sem identificação e com placas indicando a venda ou aluguel ou ainda lotes com edificações em processo de construção. Nestes casos os mesmos não foram considerados na análise e os lotes foram identificados no mapa utilizando-se a cor branca e indicados na legenda como: lotes com usos não identificados.

A classificação dos usos foi realizada no software ArcGIS 10.1 - módulo ArcMap, de maneira não automática, na escala aproximada de 1:5.000.

O trabalho se baseou na identificação e mapeamento do uso de cada lote dentro das quadras, também levando em consideração, em alguns casos, conforme a legenda proposta, o porte dos estabelecimentos e sua capacidade de lotação. A título de ilustração, cita-se como exemplo de uso os "serviços de saúde", pensando nas características em relação ao porte/tamanho, subentende-se que um serviço de saúde especificado como um consultório médico e que esteja localizado em uma edificação que ocupa apenas um lote terá uma capacidade de lotação de pessoas e veículos estacionados menor que um hospital de pronto atendimento que ocupa uma quadra inteira. Neste sentido, pensando em níveis de 
qualidade ambiental, e de modo comparativo, o primeiro representará uma qualidade ambiental melhor que o segundo.

O recurso do Google Earth Pro, foi utilizado em certos casos para identificar a metragem de alguns estabelecimentos (usos), conforme sugere a legenda, pois o mesmo dispõe de uma ferramenta que possibilita determinar as medidas dos elementos que compõem a paisagem. Também se utilizou deste recurso, por possibilitar a visualização horizontal da paisagem por meio de imagens orbitais, auxiliando na melhor interpretação dos limites dos lotes.

Durante o levantamento dos usos foi constatado, em poucos pontos, uma incompatibilidade entre o arquivo vetorial disponibilizado pelo IPPUC em relação às imagens do recurso do Google Street View. Houve casos onde no arquivo vetorial existia a representação de lotes únicos, maior que os demais e que, por vezes, ocupavam metade ou toda uma quadra. Entretanto, era constatado por meio das imagens que no local existiam 2, 3 ou mais lotes, possivelmente, resultado de uma subdivisão do grande lote único. O inverso também ocorreu, quando era representada no arquivo do IPPUC a existência de divisões entre os lotes, porém na constatação das imagens os mesmos apareciam como um lote único, evidentemente maior que os demais, possivelmente oriundo de uma anexação entre lotes.

Nestes casos, quando as classes de usos eram diferentes, sempre que possível o arquivo vetorial era atualizado de maneira manual no software, a fim de melhor representar o que foi observado no local.

Para a hierarquização dos tipos de usos de acordo com as potencialidades em gerar alterações na qualidade do ambiente foi utilizada a proposta de Nucci et al. (2017), estando organizada em 4 classes de usos e em 15 índices de qualidade ambiental (QA), sendo (QA+1) e (QA-13) a melhor e a pior, respectivamente (Figura 2). 


\begin{tabular}{|c|c|c|c|}
\hline & Índice & Usos & Exemplo \\
\hline \multirow{4}{*}{ ড্ } & $Q A+1$ & $\begin{array}{c}\text { Conservação da natureza e recreação } \\
\text { em contato com a natureza }\end{array}$ & Unidades de Conservação, parques e bosques urbanos \\
\hline & QA 0 & $\begin{array}{l}\text { Recreação e salvaguarda de bens de } \\
\text { valor histórico, artístico, arquitetônico, } \\
\text { arqueológico e paisagístico }\end{array}$ & $\begin{array}{c}\text { Espaços livres de edificação: praças, jardins, playground, } \\
\text { terreno baldio }\end{array}$ \\
\hline & QA -1 & $\begin{array}{l}\text { Recreação e salvaguarda de bens de } \\
\text { valor histórico, artístico, arquitetônico, } \\
\text { arqueológico e paisagístico }\end{array}$ & $\begin{array}{l}\text { Espaços edificados como clubes esportivos sociais, de } \\
\text { campo e náuticos }\end{array}$ \\
\hline & QA -2 & $\begin{array}{c}\text { Atividades econômicas compativeis com } \\
\text { a manutenção e recuperação dos } \\
\text { serviços ambientais }\end{array}$ & $\begin{array}{c}\text { Pesquisa, manejo e educação ambiental, captação e } \\
\text { água mineral }\end{array}$ \\
\hline \multirow{4}{*}{ 嵌 } & QA -3 & Residencial unifamiliar & Edificações de até 4 pavimentos \\
\hline & QA -4 & Conjunto residencial & Edificações acima de 4 pavimentos \\
\hline & QA -5 & $\begin{array}{l}\text { Serviço de pequeno porte com lotação } \\
\text { de até } 100 \text { pessoas }\end{array}$ & $\begin{array}{c}\text { Educação e cuidados infantis, clínicas (dentária, médica } \\
\text { e veterinária), cartório, funerária, local de reunião, } \\
\text { cabeleireiros, lavanderias, escritórios em geral, agência } \\
\text { bancária, manutenção residencial, ensino pré-escolar, } \\
\text { casa de repouso, flats }\end{array}$ \\
\hline & QA -6 & $\begin{array}{l}\text { Serviço e comércio de pequeno porte. } \\
\text { Máximos: } 1.500 \mathrm{~m}^{2} \text { de área construída, } \\
100 \text { lugares, } 40 \text { vagas de estacionamento }\end{array}$ & $\begin{array}{c}\text { Açougue, mercearia, padaria, bar lanchonete, sorveteria, } \\
\text { restaurante, local de culto }\end{array}$ \\
\hline \multirow{3}{*}{$\begin{array}{l}\stackrel{m}{山} \\
\tilde{\omega} \\
\vdots \\
\end{array}$} & QA -7 & $\begin{array}{l}\text { Serviço e comércio de médio porte. } \\
\text { Máximos: } 7.500 \mathrm{~m}^{2}, 500 \text { lugares. }\end{array}$ & $\begin{array}{c}\text { Asilo, estabelecimento de ensino, delegacia de polícia, } \\
\text { local de reunião, academia, clube, comércio de alimentos, } \\
\text { serviços de saúde, autoescola }\end{array}$ \\
\hline & QA -8 & $\begin{array}{l}\text { Serviço e comércio de grande porte. } \\
\text { Acima de } 7.500 \mathrm{~m}^{2} \text { e de } 500 \text { lugares. }\end{array}$ & $\begin{array}{l}\text { Universidades, serviços de saúde, local de reunião, local } \\
\text { de culto, supermercado }\end{array}$ \\
\hline & QA -9 & $\begin{array}{l}\text { Serviços e comércio de grande porte. } \\
\text { (acima de } 7.500 \mathrm{~m}^{2} \text {, mais de } 500 \text { lugares, } \\
200 \text { vagas de estacionamento) e oficinas. }\end{array}$ & $\begin{array}{l}\text { Garagem de ônibus, caminhões e de máquinas, aluguel } \\
\text { de veículos, centro de inspeção, penitenciária, quartéis, } \\
\text { quadra de escola de samba, terminal rodoviário, estações } \\
\text { de metrô e de trem. Mecânica em geral e ferro velho }\end{array}$ \\
\hline \multirow{4}{*}{ 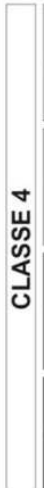 } & QA -10 & Atividade industrial nivel 1 & $\begin{array}{l}\text { Fabricação de artigos de vestuário, de artefatos de papel, } \\
\text { de máquinas para escritório, equipamentos de informática. } \\
\text { Lavanderia hospitalar, marcenaria, serralheria, gráfica, } \\
\text { posto de combustiveis, funilaria, aeroportos e helipontos }\end{array}$ \\
\hline & QA -11 & Atividade industrial nivel 2 & $\begin{array}{c}\text { Fabricação de produtos alimentícios e bebidas; de produ- } \\
\text { tos têxteis (sem operações de fiação, tecelagem, benefi- } \\
\text { ciamento e tingimento), de artefatos de couro, de produtos } \\
\text { de plástico, madeira, palha, cortiça e bambu }\end{array}$ \\
\hline & QA -12 & Atividade industrial nível 3 & $\begin{array}{l}\text { Fabricação de conservas, produtos de cereais, refino de } \\
\text { óleos. Automobilistica. Extração de carvão, petróleo. } \\
\text { Gestão de resíduos sólidos, ETA e ETE. Depósito de } \\
\text { inflamáveis. Comércio de fogos de artificio. Cemitérios }\end{array}$ \\
\hline & QA -13 & Atividade industrial nivel 4 & $\begin{array}{l}\text { Fabricação de óleos, rações, celulose. Curtimento. Fabri- } \\
\text { cação de coque, refino de petróleo, intermediários para fer- } \\
\text { tilizantes, resinas e fibras. Fabricação de explosivos, sol- } \\
\text { ventes, cimento, cal, telhas, produção de gusa, ferro e aço }\end{array}$ \\
\hline
\end{tabular}

Figura 2 - Proposta de legenda para a correlação entre usos da terra e qualidade ambiental. Fonte: Nucci et al., 2017.

Cabe salientar que a legenda proposta por Nucci et al. (2017) apresenta apenas alguns exemplos de usos em seu layout, e que a mesma vem acompanhada de uma listagem que especifica centenas de usos, separadas por índices de qualidade ambiental (Anexo 1). 


\section{Resultados e Discussões}

Como principal resultado, obteve-se o mapa de qualidade ambiental da parte superior da bacia hidrográfica do rio Belém - Curitiba/Paraná/Brasil (Figura 3).

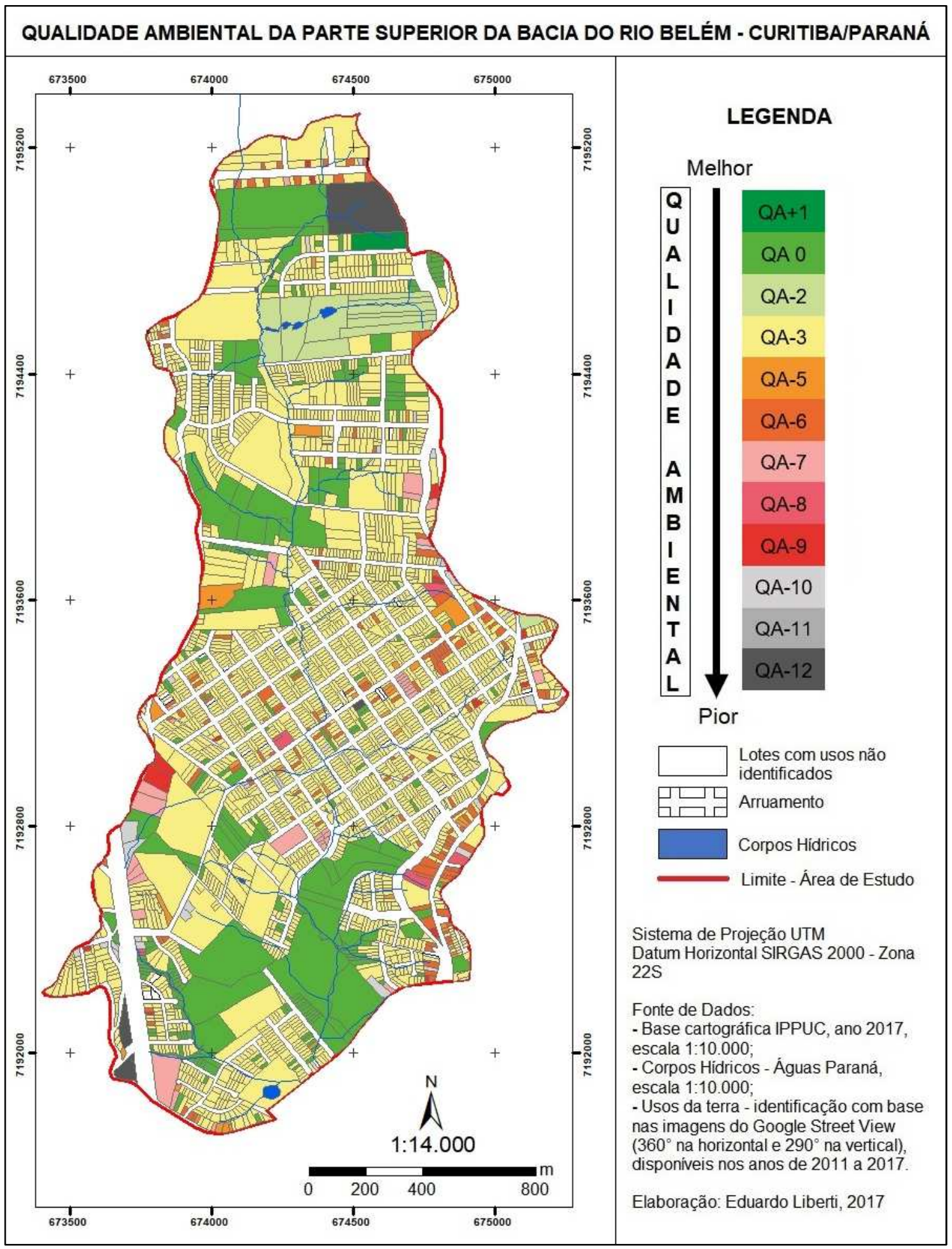

Figura 3 - Mapa de qualidade ambiental da parte superior da bacia hidrográfica do rio Belém (Curitiba, Paraná). Organização: os autores, 2017. 
Conforme as características do uso da terra, foram identificados na área de estudo 12 entre os 15 índices de qualidade ambiental, integrando as 4 classes da legenda proposta. A quantificação da área de cada classe de uso da terra e índices de qualidade ambiental, assim como as porcentagens em relação à área total, podem ser observados no Quadro 1.

\begin{tabular}{|c|c|c|c|}
\hline & $\begin{array}{l}\text { Índices de } \\
\text { Qualidade } \\
\text { Ambiental }\end{array}$ & $\begin{array}{l}\text { Área } \\
\left(\mathrm{Km}^{2}\right)\end{array}$ & $\begin{array}{c}\text { \% em relação } \\
\text { à área total }\end{array}$ \\
\hline \multirow{3}{*}{ Classe 1} & +1 & 0,01 & 0,34 \\
\hline & 0 & 0,63 & 18,18 \\
\hline & -2 & 0,12 & 3,38 \\
\hline \multirow{3}{*}{ Classe 2} & -3 & 1,68 & 48,39 \\
\hline & -5 & 0,05 & 1,32 \\
\hline & -6 & 0,08 & 2,37 \\
\hline \multirow{3}{*}{ Classe 3} & -7 & 0,06 & 1,82 \\
\hline & -8 & 0,01 & 0,35 \\
\hline & -9 & 0,02 & 0,49 \\
\hline \multirow{3}{*}{ Classe 4} & -10 & 0,03 & 0,90 \\
\hline & -11 & 0,01 & 0,34 \\
\hline & -12 & 0,05 & 1,53 \\
\hline $\begin{array}{l}\text { Lotes com usos não } \\
\text { identificados }\end{array}$ & Cor branca & 0,01 & 0,38 \\
\hline $\begin{array}{c}\text { Tráfego (ruas, } \\
\text { avenidas, ciclovias e } \\
\text { ferrovias) }\end{array}$ & - & 0,71 & 20,21 \\
\hline TOTAL & 12 & 3,48 & 100 \\
\hline
\end{tabular}

Quadro 1 - Quantificação das classes de uso da terra e índices de qualidade ambiental da parte superior da bacia hidrográfica do rio Belém (Curitiba, Paraná). Organização: os autores, 2017. 
Destaca-se que os lotes com usos não identificados e as vias de tráfego não foram consideradas na análise da qualidade ambiental urbana.

A seguir, são descritas e ilustradas com fotografias as classes de uso da terra e índices de qualidade ambiental encontradas na parte superior da bacia do rio Belém. Os índices ( $Q A$-1, QA -4 e QA -13), referentes as classes 1, 2 e 4, respectivamente, não foram encontrados na área de estudo.

\subsection{Classe 1}

A classe 1 está estruturada em 4 índices de qualidade ambiental. O primeiro índice (QA +1) refere-se aos usos relacionados à preservação e conservação da natureza, pesquisa, ecoturismo, educação ambiental e recreação em contato com a natureza. Esse é o melhor índice considerado na legenda, uma vez que a vegetação e os corpos hídricos são elementos importantes desses espaços, contribuindo para a melhoria da qualidade ambiental. Como exemplo de uso pode-se citar os parques urbanos destinados à conservação do patrimônio ambiental e ao lazer. Foi encontrado apenas um uso relacionado a esse nível $(Q A+1)$, o Parque Municipal Nascentes do Belém, localizado na parte norte da área de estudo, no bairro Cachoeira.

O segundo índice (QA 0) refere-se aos usos com as seguintes características: espaços livres de edificação destinados à recreação ativa e passiva; valorização e salvaguarda dos bens de valor histórico, artístico, arquitetônico, arqueológico e paisagístico. As praças, jardins, terrenos baldios, dentre outros, são exemplos de usos. Esses usos são considerados como sem efeito ao índice de qualidade ambiental. Ocupando cerca de $16 \%$ da área de estudo, o nível (QA 0) representa o segundo maior valor dentre os usos identificados, destacando-se os grandes lotes representados por terrenos baldios dispersos na parte norte da área estudada.

Os dois índices QA -1 e QA -2 referem-se aos espaços edificados específicos e de atividades econômicas compatíveis com os serviços ambientais, respectivamente. O índice QA -1 tem como exemplo de uso os espaços ocupados por clubes esportivos sociais: clubes de campo e náuticos, usos não identificados na área de estudo. O índice QA -2 apresenta como exemplos de usos as atividades de pesquisa e educação ambiental, atividades de manejo sustentável (agroindústria, atividades agroflorestais, agropecuária, dentre outros) e foram representados com um pouco mais de $3 \%$, em uma parcela da parte norte da área de estudo: um grande lote com características rurais, sendo possível identificar o desenvolvimento de atividades agrícolas e de pecuária no local. Também entrou nessa 
classificação o Horto Municipal Barreirinha, que apresenta uma pequena parte no limite leste da bacia.

Por disporem de edificações e por suas características de utilização, mesmo com presença de espaços com vegetação em alguns deles, tais índices foram inseridos como os primeiros com os usos que contribuem para a diminuição da qualidade ambiental.

No Quadro 2 é possível visualizar exemplos de algumas imagens da área de estudo referentes aos usos citados.

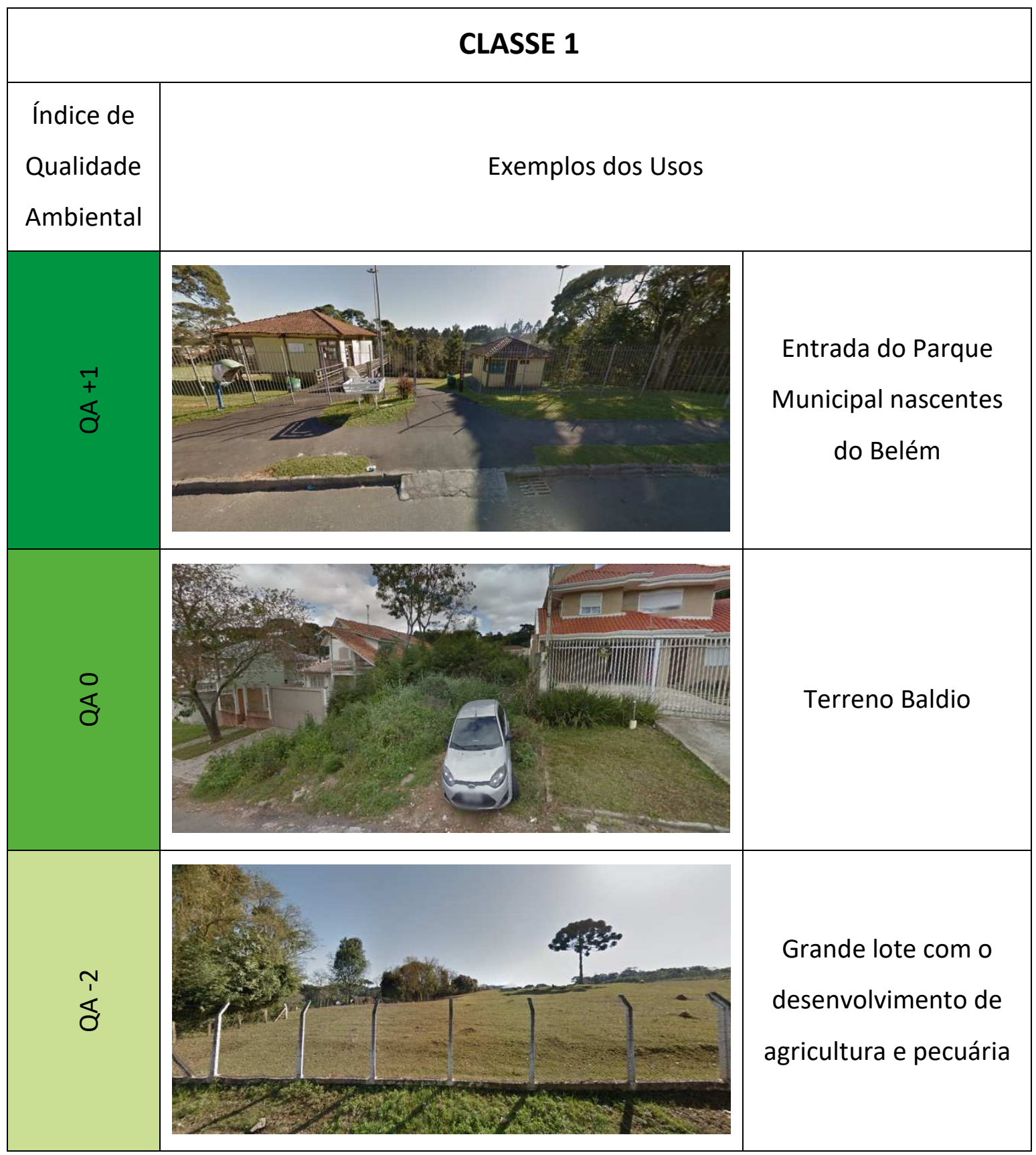

Quadro 2 - Classe 1: índice de qualidade ambiental conforme as características de uso da terra. Organização: os autores, 2017. Fonte das imagens: Google Street View, 2015. 


\subsection{Classe 2}

Na sequência da legenda, passa-se para a classe 2, que também é composta por 4 índices, que colaboram para a diminuição da qualidade ambiental na ordem de QA -3 até a QA -6. Essa classe refere-se aos usos residenciais e de comércio e serviços de pequeno porte. A fim de exemplificar, algumas imagens podem ser visualizadas no Quadro 3.

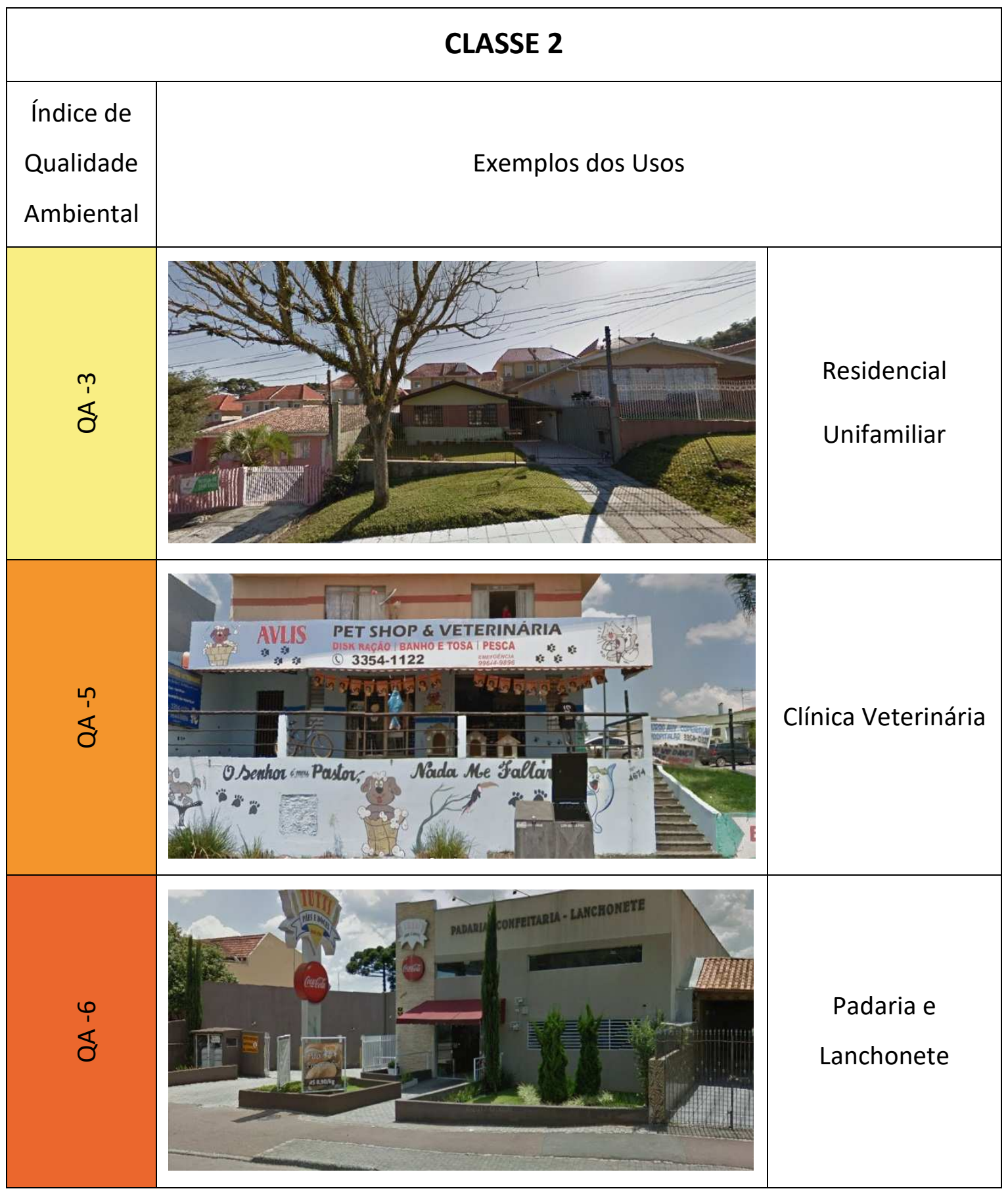

Quadro 3 - Classe 2: índice de qualidade ambiental conforme as características de uso da terra. Organização: os autores, 2017. Fonte das imagens: Google Street View, 2015. 
Os usos residenciais foram subdivididos em dois índices, sendo QA -3 referentes às edificações residenciais unifamiliar de até 4 pavimentos e o índice QA -4 às edificações acima de 4 pavimentos, caracterizado por conjuntos residenciais. O índice QA -3 representa, com pouco mais de $48 \%$ da área estudada, o uso mais encontrado e o índice QA -4 não foi identificado na área de estudo.

Os índices QA -5 e QA -6 referem-se aos comércios e serviços, como, por exemplo, cartórios, funerárias, mercearias, lanchonetes, dentre outros, considerando, além do tipo de uso propriamente dito, o porte dos estabelecimentos em tamanho de área construída e a capacidade de lotação (número de lugares e vagas de estacionamento). As áreas ocupadas por esses índices correspondem a pouco mais de 3\% da área de estudo.

\subsection{Classe 3}

A classe 3 é composta por 3 índices que contribuem para a diminuição da qualidade ambiental e referem-se aos comércios e serviços de médio e grande porte. A subdivisão dos índices considera o porte dos estabelecimentos e a capacidade de lotação. Dentre os usos dessa classe e que foram encontrados na área de estudo, pode-se citar os estabelecimentos de ensino (QA -7), supermercados (QA -8) e mecânicas de automóveis (QA -9), exemplificados com imagens no Quadro 4. A área ocupada pelos usos dessa classe somam pouco mais de $2 \%$ do total. 


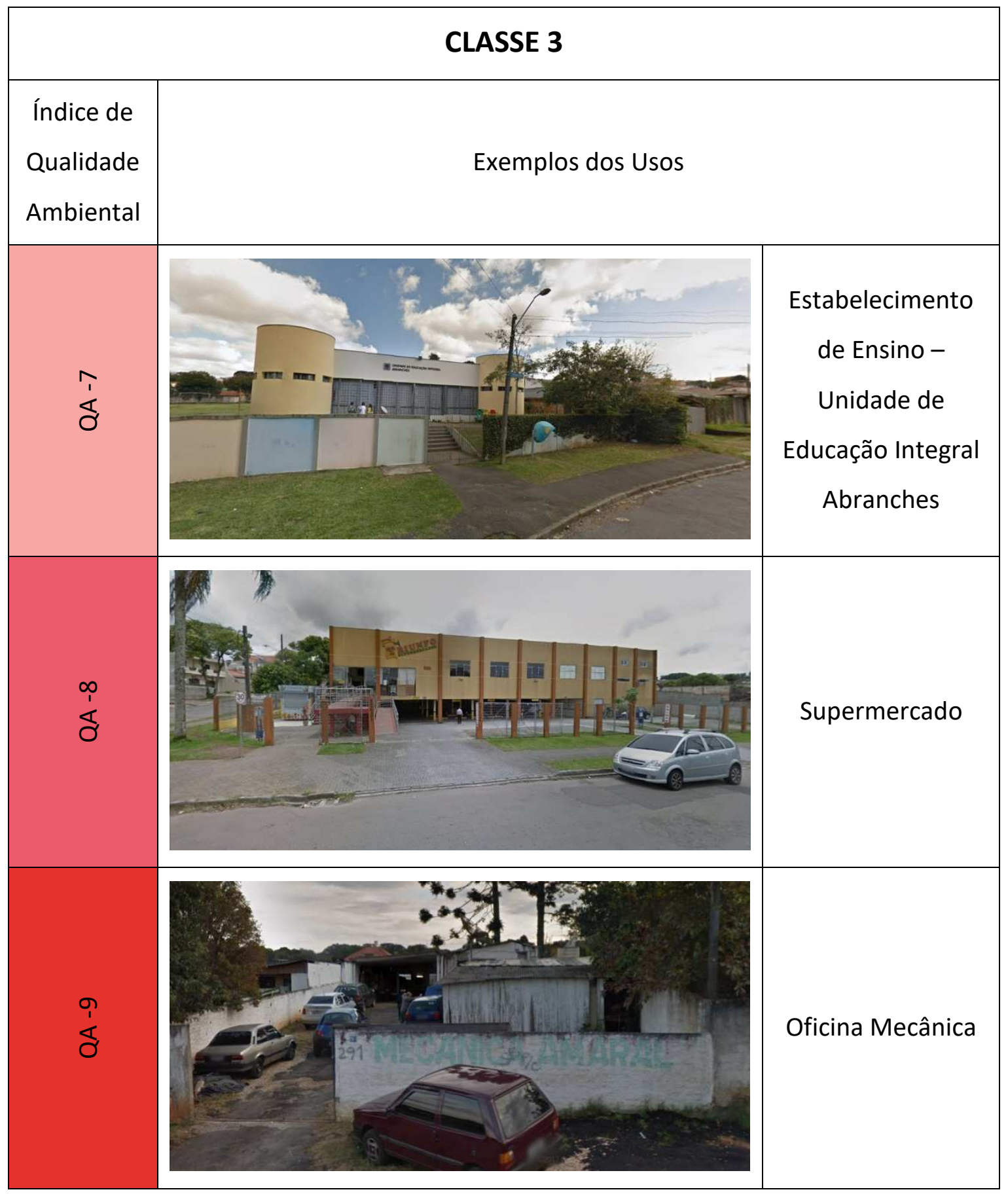

Quadro 4-Classe 3: índice de qualidade ambiental conforme as características de uso da terra. Organização: os autores, 2017. Fonte das imagens: Google Street View, 2015.

\subsection{Classe 4}

A última classe agrupa os usos industriais, com maior potencial para diminuir a qualidade ambiental em área urbana, e é composta por 4 índices, na ordem de (QA -10) até (QA -13), 
de acordo com os processos desenvolvidos pelos mesmos e que podem gerar impactos ambientais negativos, como, por exemplo, o nível de ruído e vibração, além do fluxo de veículos de carga e descarga e de pessoas, dentre outros aspectos.

Cabe destacar que o uso "cemitério" foi considerado nessa classe, no índice (QA -12), sendo esse o único uso de caráter não industrial. Nucci et al. (2017) justificam a colocação do uso "cemitério" nesse nível citando Kemerich et al. (2016), pois afirmam que "os cemitérios, como qualquer outra instalação que afete as condições naturais do solo e das águas subterrâneas, são classificados como atividade com risco de contaminação ambiental".

A área ocupada pelos usos referentes a essa classe representa pouco mais de $2 \%$ do total e na área de estudo, o pior índice de qualidade ambiental encontrado foi o QA -12, com a indetificação de dois cemitérios.

Observa-se no Quadro 5 imagens referentes aos usos da classe 4 encontrados na área de estudo.

Analisando-se a distribuição espacial da qualidade ambiental (Figura 3), observa-se que os melhores índices, referentes a classe 1, representados por tons na cor verde, concentram-se nas partes norte e sul da área de estudo.

O índice $Q A-3$, referente à classe 2 , representado na tonalidade de cor amarela e constituído pelo uso residencial, estão amplamente distribuídos na área de estudo. Constata-se ainda, quando se observa os usos referentes aos comércios e serviços de pequeno e grande porte, representados nos tons de alaranjado, rosa e vermelho, referentes as classes 2 e 3 da legenda, que os mesmos se encontram distribuídos esparsamente ao longo da área de estudo, com apenas poucas concentrações nas partes leste e oeste. É frequente a proximidade entre os melhores e piores índices, compreendendo assim uma incompatibilidade entre os usos.

Uma questão preocupante em relação ao melhor e pior índice de qualidade ambiental (QA +1 e QA -12), respectivamente, que se pôde levantar, refere-se à localização do cemitério "Jardim da Paz" à montante e adjacente ao Parque Municipal Nascentes do Belém. De acordo com a Prefeitura de Curitiba (2017), o Parque Nascente do Belém foi criado no ano de 2001 com o objetivo de garantir a preservação ambiental das nascentes do rio Belém, sendo esse um dos principais corpos hídricos do município. Trata-se de uma situação em 
que se pode questionar sobre o potencial impacto ambiental que o cemitério pode causar estando tão próximo de um parque urbano. Um estudo detalhado da evolução da paisagem nessa área de conflito social e ambiental pode ser encontrado em Conci et al. (2018).

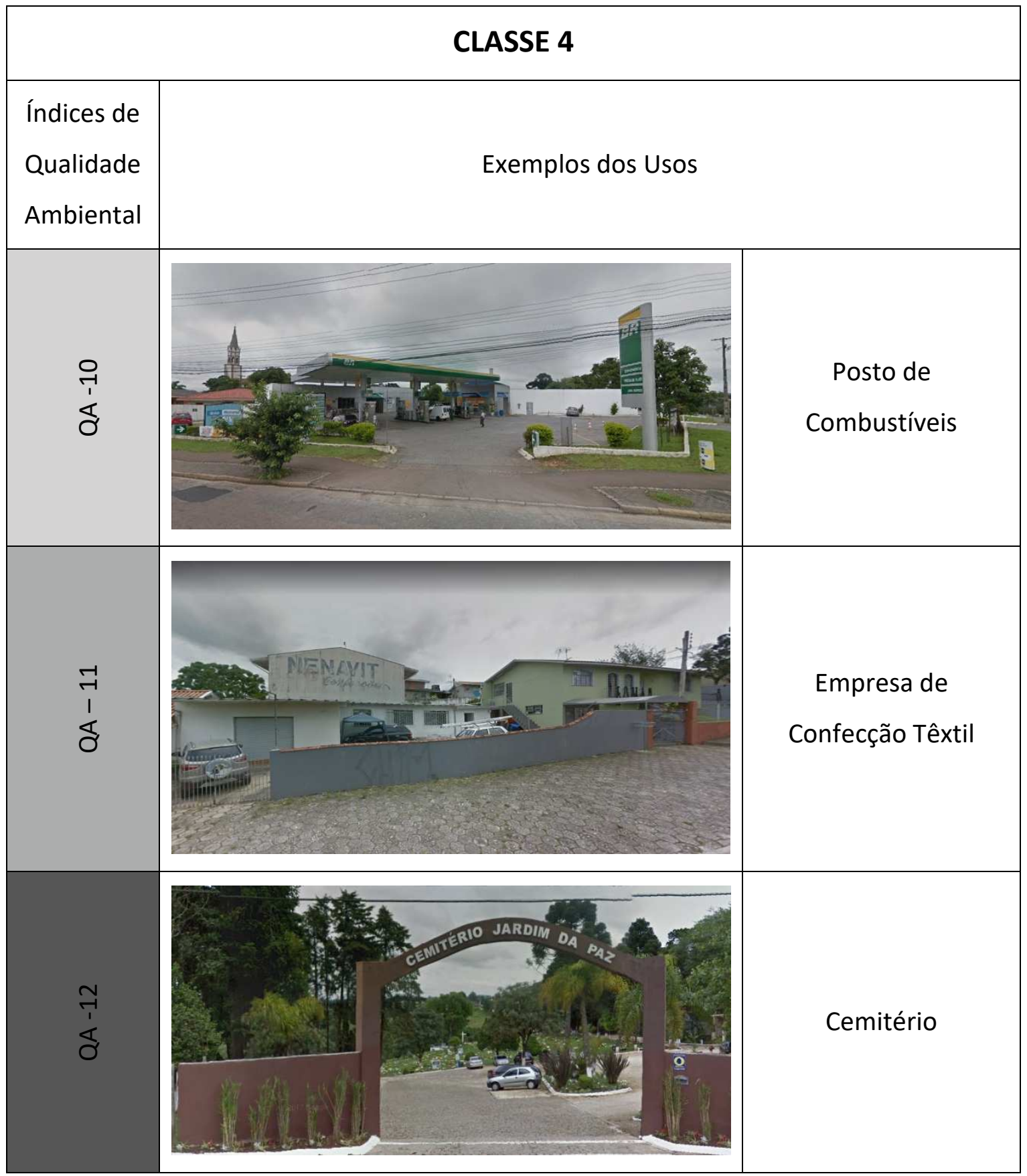

Quadro 5 - Classe 4: índice de qualidade ambiental conforme as características de uso da terra. Organização: os autores, 2017. Fonte das imagens: Google Street View, 2015.

Diferentes análises poderiam ser elaboradas com base no mapeamento e quantificação detalhados do uso da terra e sua relação com a qualidade ambiental, entretanto, o objetivo deste trabalho foi de aplicar e testar a proposta de legenda. 


\section{Conclusão}

Com base na legenda proposta por Nucci et al. (2017), foi possível identificar e mapear, lote a lote, o uso da terra e sua relação com a qualidade ambiental da parte superior da bacia hidrográfica do rio Belém.

A consideração do que se passa em nível de lote é muito importante, pois a análise, nesse nível de detalhamento, valoriza e respeita o cotidiano do cidadão que sofre com a mistura de usos incompatíveis, e fornece subsídios para o cumprimento do Estatuto da Cidade, ou seja, quando esse instrumento afirma que se deve evitar "a proximidade de usos incompatíveis ou inconvenientes" (BRASIL, 2001), a mesma sugestão é dada pela Organização Mundial da Saúde ao afirmar que o planejamento deve auxiliar na obtenção de uma alta qualidade ambiental em todas as áreas, por segregar os usos poluidores (BARTON; TSOUROU, 2000).

A legenda proposta para o mapeamento do uso da terra mostrou-se de fácil entendimento e aplicação. A utilização do recurso referente ao Google Street View facilitou a interpretação da paisagem por meio das imagens disponibilizadas, apresentando-se como uma importante ferramenta de auxílio ao mapeamento.

Considerar a qualidade ambiental urbana nos planejamentos e ordenamentos territoriais é de grande significância, dessa maneira, o mapeamento do uso da terra, assim como métodos para realizar tais mapeamentos, mostram-se como uma valorosa ferramenta de análise.

Além disso, representar a paisagem de maneira clara e objetiva pode apresentar-se como um importante subsídio para a participação popular nos processos relacionados ao planejamento urbano.

\section{Agradecimentos}

Os autores agradecem o apoio financeiro da CAPES pela concessão das bolsas de mestrado ao primeiro autor e de pós-doutorado à segunda autora e ao CNPq pela bolsa de produtividade em pesquisa ao terceiro autor. 


\section{Referências bibliográficas}

ALBERTI, Marina. Advances in urban ecology. University of Washington, Seattle, Washington, USA: Springer, 2008, 366p. ISBN: 9780387755106.

BARTON, Hugh; TSOUROU, Catherine. Health urban planning. A WHO guide to planning for people. Londres: Spon Press (em nome da Organização Mundial da Saúde - WHO), 2000, 184p. ISBN: 0415243270.

BOLLMANN, Harry. A e EDWIGES, Thiago. Avaliação da qualidade das águas do Rio Belém, Curitiba-PR, com o emprego de indicadores quantitativos e perceptivos. Engenharia Sanitária e Ambiental (Revista Eletrônica). Vol.13 - № 4 - $\quad$ out/dez 2008, p. 443-452. Disponível em: http://www.scielo.br/scielo.php?script=sci arttext\&pid=S1413-41522008000400013 Acesso em: out. 2017. DOI: http://dx.doi.org/10.1590/S1413-41522008000400013.

CAVALHEIRO, Felisberto. Urbanização e alterações ambientais. In: TAUK, S.M. Análise Ambiental: uma visão multidisciplinar. Unesp-Fapesp, São Paulo, 1991, p. 88-99. ISBN: 8571390991.

CONCI, Janete. L.; FARIA, Helena. M.; NUCCI, João. C.; FÁVERO, Oriana. A. Evolução das paisagens do Parque Municipal Nascentes do Belém e arredores (Curitiba-PR). Revista Nacional de Gerenciamento de Cidades. Tupã, v. $06, \quad$ n. 37, 2018, p. 49-67. Disponível em: http://www.amigosdanatureza.org.br/publicacoes/index.php/gerenciamento de cidades/article/view/1509. Acesso em: abril de 2018. ISSN: 23188472. DOI: http://dx.doi.org/10.17271/2318847263720181509.

CURITIBA. Secretaria Municipal de Meio Ambiente. Áreas Verdes. Parques e Bosques. Disponível em: http://www.curitiba.pr.gov.br/conteudo/parques-e-bosques-parque-municipal-nascentes-do-belem/314. Acesso em: out. 2017.

DOUGLAS, Ian. The urban environment. Londres, Edward Arnold (Publishers) Ltda, 1983, 229p. ISBN: 0713163925.

ESTÊVEZ, Laura. F; NUCCI, João. C. A questão ecológica urbana e a qualidade ambiental urbana. Geografar Curitiba-PR, v. 10, n. 1, 2015, p. 26-49. Disponível em: https://revistas.ufpr.br/geografar/article/view/37677. Acesso em: agosto de 2017 ISSN: 1981089X. DOI: http://dx.doi.org/10.5380/geografar.v10i1.

HAAREN, Christina. V; GALLER, Carolin; OTT, Stefan. Landscape planning. The basis of sustainable landscape development. Leipzig: Gebr. Klingenberg Buchkunst - GmbH. Federal Agency for Nature Conservation. Federal Agency for Nature Conservation, Field Office Leipzig, 2008. Disponível em: https://www.bfn.de/fileadmin/MDB/documents/themen/landschaftsplanung/landscape_planning basis.pdf . Acesso em: novembro de 2017.

HOUGH, Michael. Naturaleza y Ciudad. Planificación Urbana y Processos Ecológicos. Barcelona: Editora Gustavo Gili, 1998, 316p. ISBN: 842521632X.

KEMERICH, PEDRO; UCKER, FERNANDO. E.; BORBA, WILLIAN. F. Cemitérios como Fonte de Contaminação Ambiental. Site Scientific American Brasil, Editora: Segmento, 2016. Disponível em: http://www2.uol.com.br/sciam/artigos/cemiterios como fonte de contaminacao ambiental.html. Acesso em: out. 2017.

KIEMSTEDT, Hans; HAAREN, Christina. V; MÖNNECKE, M; OTT, Stefan. Landscape Planning. Contents and Procedures. Bonn: Federal Ministry for the Environment, Nature Conservation and Nuclear Safety. 1998, 39p.

LIBERTI, Eduardo; NUCCI, João. C. Uso e Cobertura da Terra: Avaliação da Qualidade Ambiental do Bairro Parolin, Curitiba/Paraná. Espaço e Geografia - Brasília-DF, v. 20, n. 1, 2017, p. 179-200. Disponível em: http://www.Isie.unb.br/espacoegeografia/index.php/espacoegeografia/article/view/423/285. Acesso em: out. 2017. ISSN: 15169375.

MARCUS, Melvin. G.; DETWYLER, Thomas. R. Urbanization and environment. Bermont/Cal., Duxbury Press, 1972, 286p. ISBN: 9780878720347.

McHARG, Ian. Design with Nature. Nova York. Back Edition, 1971, 198p. ISBN: 0385021429; 9780385021425. MOTA, S. Urbanização e meio ambiente. Rio de Janeiro: ABES (Associação Brasileira de Engenharia Sanitária e Ambiental, 1999, 352p. ISBN: 9788575637944. 
NUCCI, João. C; VALASKI, S; ESTÊVEZ, L, F; TONETTI, E. M. Uso da terra e qualidade ambiental urbana: uma proposta de legenda para mapeamento. (2017). Revista GEOgraphia, Rio de Janeiro, (No Prelo).

NUCCI, João. C. Qualidade ambiental e adensamento urbano: Um estudo de ecologia e planejamento da paisagem aplicado ao distrito de Santa Cecília (MSP). Edição do Autor, 2008. E-book. Disponível em: http://www.labs.ufpr.br/site/arquivos/qldade_amb_aden_urbano.pdf. Acesso em: out. 2017. ISBN: 9788590825104.

SUKOPP, Hebert; WERNER, Peter. Naturaleza en las ciudades. Madrid: Mopt, 1991, 222p. ISBN: 847433781X.

SPIRN, Anne. W. O jardim de granito. São Paulo: Edusp, 1995, 345p. ISBN: 8531401585.

TONETTI, Emerson. L. Potencialidades de Adensamento Populacional por Verticalização das Edificações e Qualidade Ambiental Urbana no Município de Paranaguá, Paraná, Brasil. (Tese de Doutorado em Geografia). Universidade Federal do Paraná. Curitiba. 2011, 235p.

VALASKI, Simone.; NUCCI, João. C. Estrutura e dinâmica da paisagem do município de Curitiba/PR. Subsídios para participação popular no desenvolvimento urbano. Beau Bassin: Novas Edições Acadêmicas, 2018, 144p. ISBN: 9786202181716. 
ANEXO 1: Proposta de hierarquização de usos da terra para determinação da qualidade ambiental urbana. (NUCCl, et al. 2017)

$\mathrm{QA}=+1$ (Qualidade Ambiental $=+1)$

Preservação e conservação da natureza, pesquisa, ecoturismo, educação ambiental e recreação em contato com a natureza. Exemplos: Unidades de Conservação da Natureza, tais como parques urbanos destinados à conservação do patrimônio ambiental e ao lazer.

$\mathrm{QA}=0$

Espaços livres de edificação destinados à recreação ativa e passiva; valorização e salvaguarda dos bens de valor histórico, artístico, arquitetônico, arqueológico e paisagístico. Ex.: praças, jardins, terrenos baldios, etc.

$Q A=-1$

Espaços edificados destinados à preservação, valorização e salvaguarda dos bens de valor histórico, artístico, arquitetônico, arqueológico e paisagístico e espaços públicos ou privados ocupados por clubes esportivos sociais; clubes de campo e clubes náuticos.

$Q A=-2$

Atividades econômicas compatíveis com a manutenção e recuperação dos serviços ambientais por elas prestados, em especial os relacionados às cadeias produtivas da agricultura e do turismo, de densidades demográfica e construtiva baixas. Ex.: atividades de pesquisa e educação ambiental, atividades de manejo sustentável (agroindústria, atividades agroflorestais, agropecuária, dentre outras); captação de água mineral/potável de mesa.

$Q A=-3$

Residencial: edificações de até 4 pavimentos.

$\mathrm{QA}=-4$

Residencial: conjunto residencial acima de 4 pavimentos.

$Q A=-5$ (serviços de pequeno porte / lotação de até 100 pessoas).

Serviço público social de pequeno porte, local de reunião ou de eventos com lotação de até 100 pessoas; prestação de serviços pessoais e profissionais (liberais, técnicos ou universitários ou de apoio ao uso residencial) de âmbito local, serviços de administração e públicos. Ex.: bibliotecas, estabelecimentos destinados à educação e cuidados infantis ou de alunos com necessidades especiais, unidades de saúde e assistência social de âmbito local (ambulatório, laboratório de análises clínicas - dentária, médica, veterinária), eletroterapia, 
"home care", agências de correios, telefônicas, cartórios, consulados, Delegacia de Ensino, Órgãos da Administração Pública federal, estadual e municipal, Posto Policial, Serviço Funerário entre outros; cabeleireiros e outros tratamentos de beleza, caixas bancárias automáticas, fotografia, lavanderias e tinturarias (não industriais), locação de fitas de vídeo, dvds, livros, etc.; escritórios, consultórios e agências de representação de negócios em geral, agência bancária, agência de empregos, de entregas de encomendas, de passagens e turismo, imobiliária, escritórios em geral, copiadoras, manutenção predial (eletricista, encanador, pedreiro, pintor, chaveiro, vidraceiro, jardineiro), costureiro, conservação, reparação e manutenção, limpeza e reparos de máquinas e de aparelhos eletrodomésticos, elétricos e eletrônicos de uso domiciliar, e de outros objetos pessoais e domésticos (bicicletas, brinquedos, canetas, cutelarias e outros), sapateiro, confecção de carimbos, maquetes e molduras, laboratório de Prótese Dentária, lapidação, oficinas de joias e relógios, ensino pré-escolar ou à prestação de serviços de apoio aos estabelecimentos de ensino seriado e não seriado, associações comunitárias, culturais e esportivas, casas de repouso, conventos, seminários, flats, hotéis, motéis, pensionatos, etc.

$\mathrm{QA}=-6$ (serviços e comércio de pequeno porte, até $1.500 \mathrm{~m} 2$ de área construída, até 100 lugares, até 40 vagas de estacionamento).

Comércio diversificado de âmbito local; serviços de saúde (sem unidade de pronto atendimento), central de armazenamento e distribuição de cargas, serviços de armazenamento e guarda de bens móveis. Ex.: armazém, mercearia, casa de carnes (açougue, avícola, peixaria), casa de massas, confecção e comercialização de alimento congelado ou comida preparada, padaria, bar, lanchonete, sorveteria, restaurantes, casas de música, salão de festas, bailes, "buffet", aluguel de vestimentas, louças, toalhas, móveis, máquinas etc.; depósitos de material, máquinas e equipamentos em geral, distribuidora de alimentos embalados ou enlatados, de bebidas, guarda e adestramento de animais, leiloeiro oficial, depósito de madeireira, serviço de aluguel equipamento, local de culto.

$\mathrm{QA}=-7$ (serviços e comércio de médio porte, até $7.500 \mathrm{~m} 2$, de 100 a 500 pessoas).

Serviços de ensino, saúde, lazer, esportes, serviços públicos, comércio de alimentação e de abastecimento. Ex.: ensino fundamental, médio e superior, ensino complementar aos cursos profissionalizantes ou de aperfeiçoamento ou à educação informal em geral, estabelecimentos de saúde e assistência social de âmbito regional; hospitais, prontosocorro; albergue, asilo, berçário, dispensário, telecentros, orfanato, local de reunião ou eventos, Comando de batalhão de policiamento de trânsito, Corpo de bombeiros, Delegacia de polícia, Forum, Juizado de menores, Tribunais, academias de ginástica, bilhar, bingo, boliche, clubes associativos, diversões eletrônicas, "Lan house", "Kart indoor", "Paintball", "war game", parque de animais selvagens, ornamentais e de lazer, pesqueiro, pista de "skate", quadras e salões de esporte para locação, associações comunitárias, culturais e esportivas, local de culto, central telefônica, estação rádio-base e torre para antenas.

$\mathrm{QA}=-8$ (serviço e comércio de grande porte, acima de $7.500 \mathrm{~m} 2$ e de 500 pessoas). 
Serviço e comércio em geral, mas de grande porte. Ex.: universidades ou outros estabelecimentos de ensino, local de reunião, evento, culto ou de alimentação, shopping center.

$\mathrm{QA}=-9$ (serviço e comércio de grande porte, acima de $5.000 \mathrm{~m} 2$, mais de 200 vagas de estacionamento e oficinas).

Serviços de armazenamento e guarda de bens móveis, comércio de produtos especiais, oficinas. Ex.: venda ou guarda de mercadorias em geral, máquinas ou equipamentos, guarda de móveis ou animais, incluindo garagem de ônibus, caminhões e de máquinas, edifíciosgaragem, aluguel de veículos e acessórios, centro de inspeção de veículos, desmanche de veículos, empresa transportadora, estacionamentos, feira de veículos, autódromo, penitenciária, quartéis, quadra de escola de samba e "Drive-in", terminal rodoviário interurbano de transporte de passageiros, terminal de ônibus urbano, estações de metrô, trem, monotrilho e demais modais de transporte público coletivo urbano, comércio de produtos agro-pecuários ou minerais (borracha natural, carvão mineral e vegetal, chifres, couro, etc); comércio de madeira bruta, de produtos químicos, adubos, fertilizantes, gomas ou resinas; ferro velho.

$\mathrm{QA}=-10$ (Atividade industrial nível 1 - sem qualquer operação de anodização, pintura e tingimento, apenas montagem).

Fabricação de artigos de vestuário e acessórios, de artefatos de papel, de equipamentos de comunicações, de máquinas para escritório e equipamentos de informática, de equipamentos de instrumentação médico-hospitalares, instrumentos de precisão e ópticos, equipamentos para automação industrial, cronômetros e relógios, de material eletrônico básico, de aparelhos e equipamentos de telefonia, radiotelefonia, televisão, rádio, informática, de produtos alimentícios e bebidas artesanais, de artigos esportivos, recreativos, de placas e cartazes, embalagem, rotulagem, encadernação e restauração de livros. Laboratório de controle tecnológico e análise química, lavanderia hospitalar, estúdio fotográfico, de gravação de vídeo, de sons, de filmagens. Soldagem, vidraçaria, cantaria, marmoraria, carpintaria, marcenaria, serralheria, gráfica, clicheria, linotipia, fotolito, litografia e tipografia. Manutenção e reparação de artefatos de metal (armeiros, ferreiros), de veículos automotores e motocicletas (alinhamento e balanceamento, amortecedores, chassis, estofamento, faróis, freios, funilaria, molas, motores, pinturas e similares), posto de abastecimento e lavagem de veículos. Abastecimento de gás natural, tais como estações de regulagem de pressão de gás e centrais de cogeração e abastecimento de água. Geração, transmissão e distribuição de energia elétrica, tais como estações e subestações reguladoras de energia elétrica e sistema de transmissão de energia elétrica, inclusive estação e subestação reguladora, usinas hidrelétricas, usinas termoelétricas, usinas eólicas, usinas fotovoltaicas, usinas de biomassa, usinas de biogás ou biometano, usinas elevatórias, barragens, diques, sangradouros e reservatórios para a geração de energia elétrica. Base aérea ou de treinamento militar; Campo para treinamento de combate contra incêndios; Central de controle de zoonoses. Transporte aéreo, tais como aeroportos, aeródromos e helipontos. 
$\mathrm{QA}=-11$ (Atividade industrial nível 2 - até $1.000 \mathrm{~m}^{2}$ de área construída).

Fabricação de produtos alimentícios e bebidas (produtos de padaria, confeitaria; sorvetes; derivados do cacau e elaboração de chocolates; fabricação de gelo (usando freon como refrigerante), engarrafamento e gaseificados de águas minerais dentre outros; fabricação de produtos têxteis (sem operações de fiação, tecelagem, beneficiamento e tingimento de fibras têxteis ou tecidos); preparação de couros e fabricação de artefatos de couro, artigos de viagem e calçados (sem operações de curtimento); fabricação de produtos de plástico, de produtos de madeira, palha, cortiça e bambu. Fabricação de peças e acessórios para veículos automotores (indústrias de montagem que não envolva transformação de matériaprima).

$\mathrm{QA}=-12$ (Atividade industrial nível 3 - potencialmente insalubres e com riscos de periculosidade).

Fabricação de produtos alimentícios e bebidas (preparação de alimentos, conservas, produtos de cereais, bebidas, refino de óleos vegetais, preparação de margarina e outras gorduras vegetais e de óleos de origem animal não comestíveis, fabricação de produtos de arroz, milho e mandioca, café e mate solúvel, dentre outros). Fabricação de produtos do fumo. Fabricação de produtos têxteis (beneficiamento e tecelagem de fibras têxteis, estamparia e texturização, alvejamento e tingimento de tecidos, dentre outros). Fabricação de papel e produtos de papel. Fabricação de álcool, cloro e álcalis, gases industriais, etc, produtos farmacêuticos, sabões e detergentes, artigos de perfumaria e cosméticos, aditivos de uso industrial, chapas, filmes e outros materiais e produtos químicos para fotografia, discos, fertilizantes fosfatados, nitrogenados e potássicos, adubos, resinas, fibras, fios, cabos e filamentos contínuos artificiais e sintéticos, defensivos agrícolas, produtos de limpeza e polimento, tintas, vernizes, esmaltes, lacas e produtos afins, carvão vegetal, velas, fungicidas, herbicidas, concentrados aromáticos naturais, artificiais e sintéticos. Fabricação de artigos de borracha. Fabricação de produtos de minerais não metálicos (vidro, artefatos de concreto, cimento e estuque, dentre outros). Reciclagem de sucatas não-metálicas. Metalurgia básica (produção de laminados de aço, metalurgia de diversos metais, fundição), processos de forja, galvanoplastia, usinagem, solda, têmpera, cementação e tratamento térmico de materiais. Fabricação de máquinas e equipamentos (motores, bombas, tratores, armas, eletrodomésticos, dentre outros). Fabricação de pilhas, baterias e acumuladores elétricos, lâmpadas e equipamentos de iluminação, geradores, transformadores, etc. Fabricação e montagem de veículos automotores. Indústria extrativista (extração de água mineral, carvão mineral, petróleo e gás natural, xisto, areias betuminosas, minérios, pedra, areia e argila, ardósia, granito, mármore, calcário/dolomita, gesso e caulim, areia, cascalho ou pedregulho, saibro, basalto, dentre outros. Local de eventos destinados à feira de exposição ou show de natureza social, esportiva, religiosa, lazer e agropecuária. Gestão integrada de resíduos sólidos, tais como depósito ou transbordo de materiais para reciclagem, usina ou estação de transbordo e de tratamento, aterros de resíduos sólidos. Estação de tratamento, reservatório, estação elevatória de água, estação de tratamento de esgoto, reservatório de retenção de água pluvial). Estação de controle e depósito de petróleo, estacionamento especial de veículos transportando produtos perigosos ou em situações de emergência. Depósitos de inflamáveis, combustíveis, álcool, inseticidas, lubrificantes, resinas, gomas, tintas e vernizes ou outros produtos químicos perigosos, 
depósito de botijões de gás, comércio e depósito de fogos de artifício e estampidos. Cemitérios.

$\mathrm{QA}=-13$ (Atividade industrial nível 4 - deve ser proibida em zona urbana).

Fabricação de produtos alimentícios: óleos, gorduras, beneficiamento de arroz, fabricação de rações balanceadas, dentre outros produtos que exigem soluções tecnológicas complexas ou onerosas para seu tratamento (preparação de carne, banha e produtos de salsicharia, pescado e conservas de peixes, crustáceos e moluscos, produção de óleos vegetais em bruto, preparação do leite, fabricação de produtos do laticínio, usinas de açúcar, fabricação de gelo (usando amônia como refrigerante); curtimento e outras preparações de couro; fabricação de celulose e pastas para fabricação de papel; fabricação de coque, refino de petróleo, elaboração de combustíveis nucleares; fabricação de asfalto; fabricação de produtos químicos (processos e operações altamente nocivas para a saúde pública e o meio ambiente): intermediários para fertilizantes, resinas e fibras, produtos petroquímicos básicos, produtos da destilação da madeira, fabricação de explosivos (pólvoras, detonantes, munição e artigos pirotécnicos), de impermeabilizantes e solventes. Fabricação de cimento, cal, telhas, tijolos, ornatos e estruturas de amianto; metalúrgica básica (produção de gusa, ferro e aço). Britamento de pedras. 